\title{
Using Human-Gaming As Cases for Strategic Management Theory
}

\author{
Ryo Sato *, Hirotaka Sunaguchi ${ }^{\dagger}$,
}

\begin{abstract}
A theory of corporate strategy has its own concept and propositions as a scientific theory. Theory of strategy has two kinds of difficulties with strategic propositions. Since the difficulties are not explicit, it had been almost impossible for us to resolve them. One kind of difficult thing is to prove a proposition. The other is ambiguity in interpreting and applying propositions. This situation should be remedied. In this paper, we propose how human games can be used as cases so that we can refute strategic propositions by one of the cases. In doing so, we show that the interpretations of a proposition will be extended, and then, business managers could get meaningful guideline for action from strategic propositions.
\end{abstract}

Keywords: strategy theory, gaming model, proposition, refutation

\section{Introduction}

A theory of corporate strategy has its own concept and propositions as a scientific theory. Theory of strategy has two kinds of difficulties with strategic propositions. Since the difficulties are not explicit, it had been almost impossible for us to resolve them. One kind of difficult thing is to prove a proposition. The other is ambiguity in interpreting and applying propositions. Therefore, managers sometimes had a hard time in finding suitable concrete implications to their business situation where important strategic decision should be applied.

In this paper, we examine three methods with different gaming models to remedy this situation of theory of corporate strategy. The games in this paper are human games. That is, the players of a game are, or supposed to be, people. Therefore, a human gaming (i.e., gaming of a human game) is different from an agent-simulation of a game, where a huge number of computer agents play a game so that characterizations of the game can be explored through population dynamics with, for instance, evolutionary stable strategies.

The idea behind all of the three methods is that, as [1] suggested, human players of a strategy

\footnotetext{
* Yokohama National University, Kanagawa, Japan

$\uparrow$ Graduate School of International Social Sciences, Yokohama National University, Kanagawa, Japan
} 
game will reveal their tacit and practical knowledge based on their business experience in the process of play. Furthermore, if we provide well-conceived games by which propositions of existing theories of strategy can be checked, especially, the games that could refute existing strategy theories, then, we can get clue about how we apply gaming simulation in research of strategy. When we try to refute a proposition, we refine the conditions of the proposition so that we can examine it in specific situation. If the proposition did not be refuted (i.e., stayed true) in such a new specific situation, then the new situation actually enhance meaningful business implications where the proposition still holds true.

This paper consists of the following sections. In section 2, we distinguish two different meaning of the word, strategy. Then, we introduce three methods to use gaming as cases of corporate strategy. In section 3, the first method is explained and characterized. Section 4 represents the second method, linguistic-and-qualitative game. In section 5, we propose a method to use qualitative-control - of - quantitative-process (QCQP) gaming models for strategy research. This third type model is main focus of this paper. Conclusion is in section 6 .

\section{Two concepts of strategy and gaming approach to them}

\section{Two Concepts of Strategy}

The concept of strategy has two meaning. They are corporate and operations strategies.

Corporate strategy defines the direction of corporate business. For instance, the founder and first CEO of Silicon Graphics International Corp., Mr. Jim Clark, said once like, "if a computer can do 3-dimensional image processing, then we can use such a computer very convenient" [2]. Fujifilm Corporation, the world's largest photograph film manufacturer, decided to apply its micro coating technology to cosmetics and health care products when they found impetuous decline of film demand. Those are examples of corporate strategy stated in natural language.

Another meaning of strategy is tactics that defines detailed planning and control of business operation. People often call tactics as operation strategy. In a usual business game setting, the decision on operation of the business such as price of products and amount of purchase of raw material, are examples of operation strategy. A payoff matrix or, a payoff function, in game theory deals with numeric value as payoff, and tries to find meaningful solution such as the Nash equilibrium. Players' move policies are sometimes called strategy of games. In practical business, routine decision making on the amount of purchase order of raw material based on expected inventory level and target stock level is an operation strategy in inventory management.

What is important in the distinction between corporate and operation strategies is that a corporate strategy implies many possible operation strategies. An operation strategy comes up with an operation process and its control mechanism, which virtually decides whether a good result will come out or not [1]. This situation is depicted in Figure 1.

In the following of this paper, "strategy" means corporate strategy, except as stated explicitly in other way. 


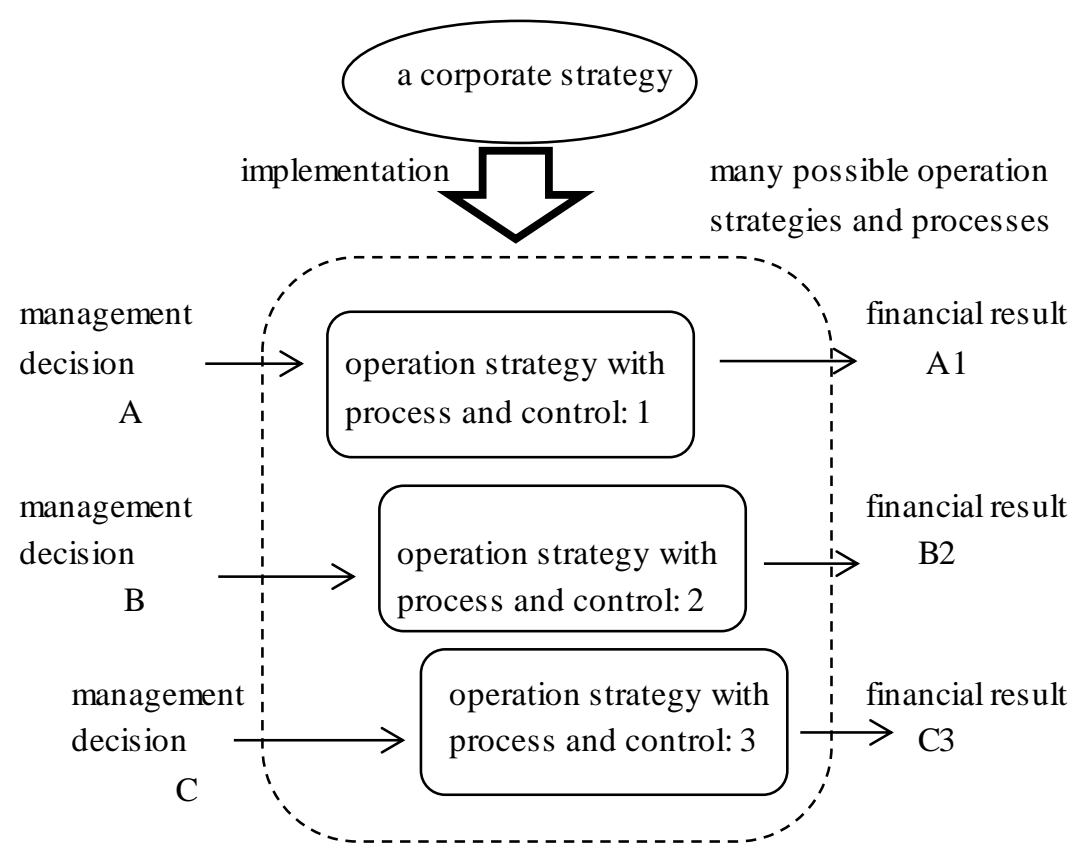

Figure 1. A corporate strategy and possible operation strategies

\section{Using Gaming as Cases}

In this paper, we discuss the following three gaming methods to evaluate strategy and characterize respective gaming models.

i) We use a gaming model with which an operation strategy is focused on. In this case, corporate strategy is not directly stated by a sentence in natural language but can be observed in resultant scenario (i.e., the game output).

ii) We use a linguistic gaming model where players directly manipulate sentences in natural language, and then, get an updated organizational state expressed in natural language.

iii) We use a combined qualitative-input and quantitative-output gaming model, where a player inputs qualitative values and gets both numerical financial outcome and scenario of strategic qualitative decision.

In the following sections, the above three types of gaming models are respectively explained and discussed.

Before we proceed, let us just mention about the use of cases in strategy theory. [4] and [5] had discussed role of cases in strategy theory. The latter pointed out possible criticism and promising points of considerations. Those points are (1) importance of research question, (2) benefit of using non-average and extreme cases, (3) cautious use of interview data not to summarize with hindsight, and (4) importance of meticulous care in presenting your theory or deduction. They will be applicable for our use of gaming result as cases. Yet, each one of our three methods primarily focuses not on theory creation like [4] and [5], but on the (possible) refutation of an existing proposition of strategy. By providing such refutable situation with gaming models, meaningful scenario could come out from gaming, and, hopefully, the players of gamed can get insightful interpretation. 


\section{Using operational gaming model for representation of strategy}

Based on [6], we show the first method in this section. It uses a "usual business game (operational game)" for strategic decision in the sense that the usual business game will be set to show the known strategic effect if appropriate operational decisions are taken in the game. Figure 2 shows the use of a business game for this purpose. In this method a usual business game is also called an operational game, because for a typical business game a player decides price, purchase amount, and/or production amount at each round to control the operation.

When we use this method, we first decide a strategic intention, and set up that intention into a gaming model. Therefore, if we focus on different strategic intention, the corresponding game will differ.

For instance, we show "learning curve" and related "economy of scale" strategy [7] in a bread manufacturing game [6]. The strategy is also called the price leadership. As like EMS (electronic manufacturing service), we consider a fictitious baking platform for other bakeries, whose name is Bake'em. The logistics process of bakery-platform business is in Figure 3. Bake'em sells two kinds of baked bread upon the bakery shops. Since it is a platform, the production scale should be large, production cost per one unit of bread is lower than usual bakery shops, and the quality of products is reasonably good. Figure 4 shows the gaming situation.

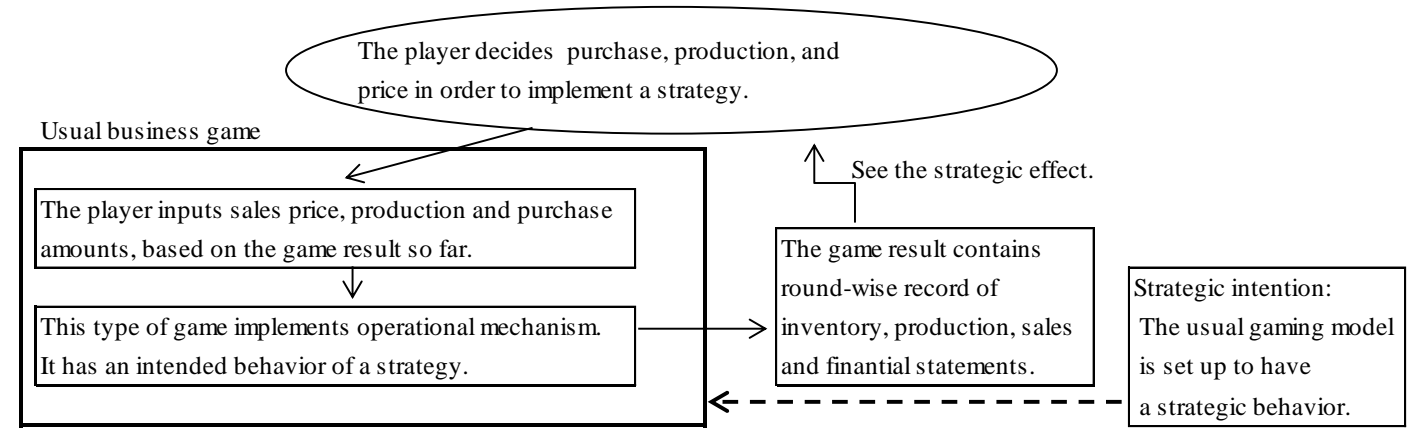

Figure 2. Strategy analysis with operational gaming model

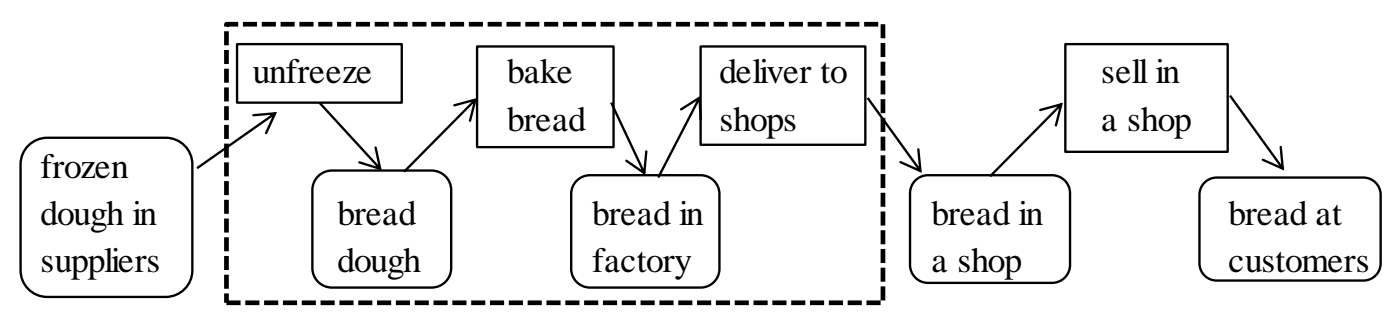

Figure 3. Logistics process of bakery-platform 


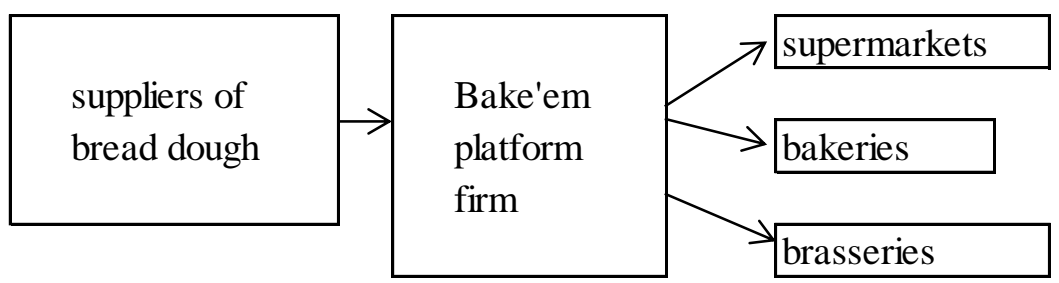

Figure 4. Gaming simulation of the operation of a platformatization strategy

Bake'em decides four input variables. They are price and production amount for respective types of bread. The basic corporate strategy here is the price leadership. It requires specific machines for mass production to attain low cost per one bread. That mass production leads Bake'em to expertise in many aspect of baking bread, especially in quality of bread and raw material, that will attract more customers. According to strategy theory such as [7], price leadership strategy relies on the learning curve that insists "if accumulated number of production from the beginning of the firm's history exceeds certain level, then the production cost per product will decrease." This kind of learning curve effect is set in the gaming model as a characteristics of the production process of the bakery platform game.

We can examine typical annual trajectory of operating profit for 30 years:

\section{A) Annual trajectory of operating profit: Case 1 (Figure 5)}

Bake'em tried to have low cost production by mass production that is much beyond the demand. At 5th year, the learning curve became effective for the first time. The low cost could not cover the deficit of revenue in this case.

\section{B) Annual trajectory of operating profit: Case 2 (Figure 6)}

In this case, Bake'em tried to get low cost production from large scale production. It ignored the fact that demand is not strong. So, it went into deep red in first two years, and then popped up (Figure 6). But, other usual platforms showed enough profit in a long run. Since the profit trajectories intersect, we use net present values for several discount rates to compare financial outcomes. Usual operations of platforms are better for those three discount rates (Table 1).

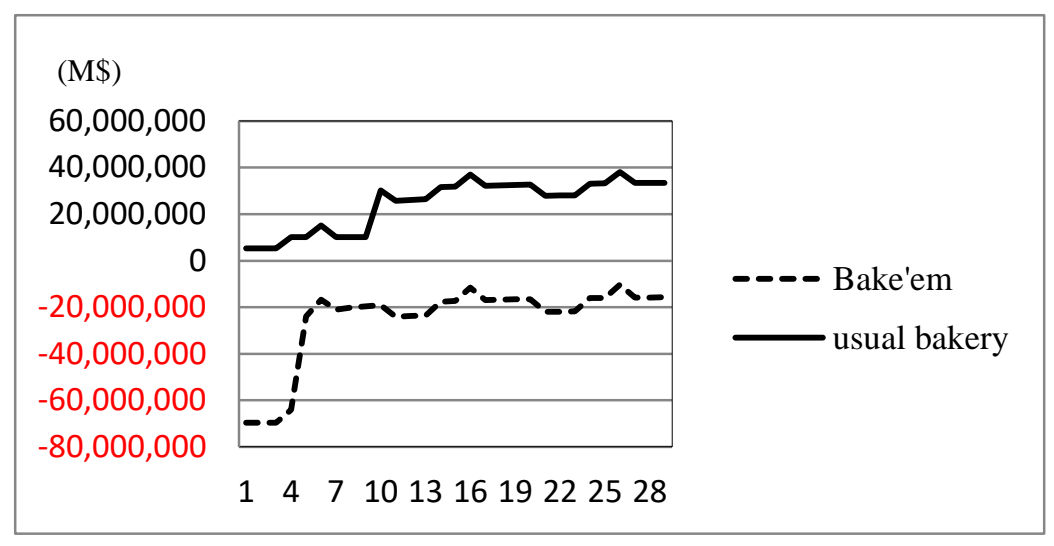

Figure 5. Development of operating profit of Bake'em gaming: Case 1 


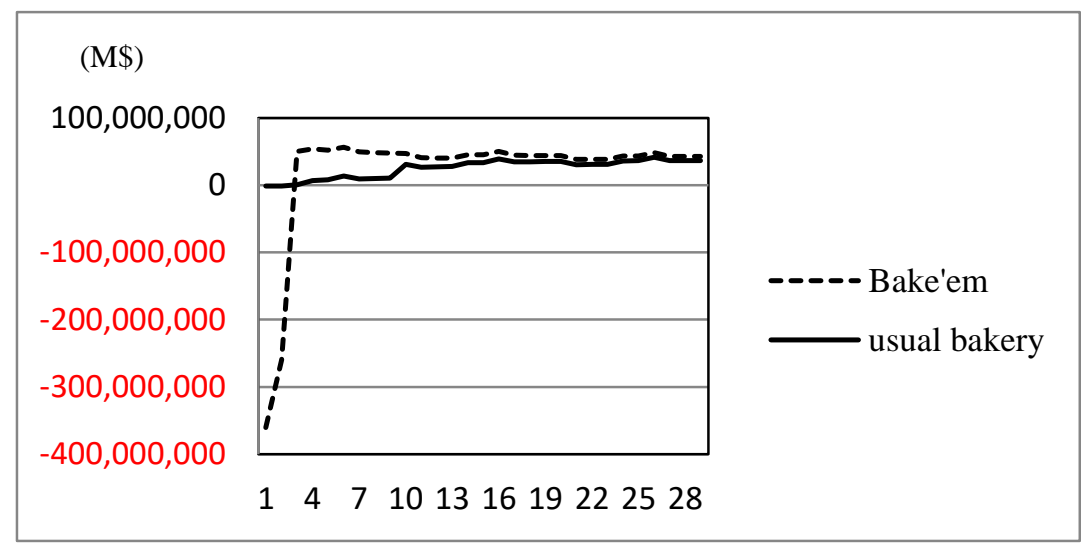

Figure 6. Development of operating profit of Bake'em gaming: Case 2

Table 1. Net Present Values of Case 2 (in M\$)

\begin{tabular}{|l|c|c|c|r|}
\hline discount rate & $1 \%$ & $2.5 \%$ & $5 \%$ & $15 \%$ \\
\hline Bake'em & $440,101,617$ & $251,205,097$ & $38,525,483$ & $270,381,390$ \\
\hline Usual bakery & $606,008,026$ & $463,399,013$ & $304,938,622$ & $77,856,552$ \\
\hline
\end{tabular}

As we pointed out in subsection 2.1, one strategy does not imply an operation mechanism. We need to decide it. Many operation mechanisms and operation strategies are possible. So, a strategy cannot be evaluated by a financial result of an operation mechanism and the management on it.

In the case of price leadership strategy and the Bake'em gaming simulation, we can summarize that even if we have the learning curve effect, we need to adjust production level to demand. Otherwise, we will see loss instead profit even in a long run. Furthermore, as usual, matching production with demand is of fundamental importance.

\section{Linguistic-and-qualitative game}

Strategy is usually expressed in natural language and contains personal recognition and hope of doing new business. In other words, a strategy is an expression of "faith" in business and world [8]. It is too abstract to be analytic. By using natural language in a structured way such as the CANVAS business modeling method explained in [9] and [10], people of an organization can express their own personal knowledge based on experience, prediction of possible result, and risk. Since we can not get any data on a new business before we start, and since there might be huge possible events that disallow to find meaningful historical development of the new business, the effectiveness of statistical methods is quite limited. In such a case, gaming is used to pull experienced people's synthetic wisdom together [1].

In this section, as shown in Figure 7, we mention an example of linguistic-and-qualitative games for corporate strategy formulation. Refer [11] for the detail. It is called Platform Strategy game (PfS game, for short). The game uses a decision table for internal state transition, the input variables are selection from a set of natural sentences on dynamic capability and platform strategy theory. 


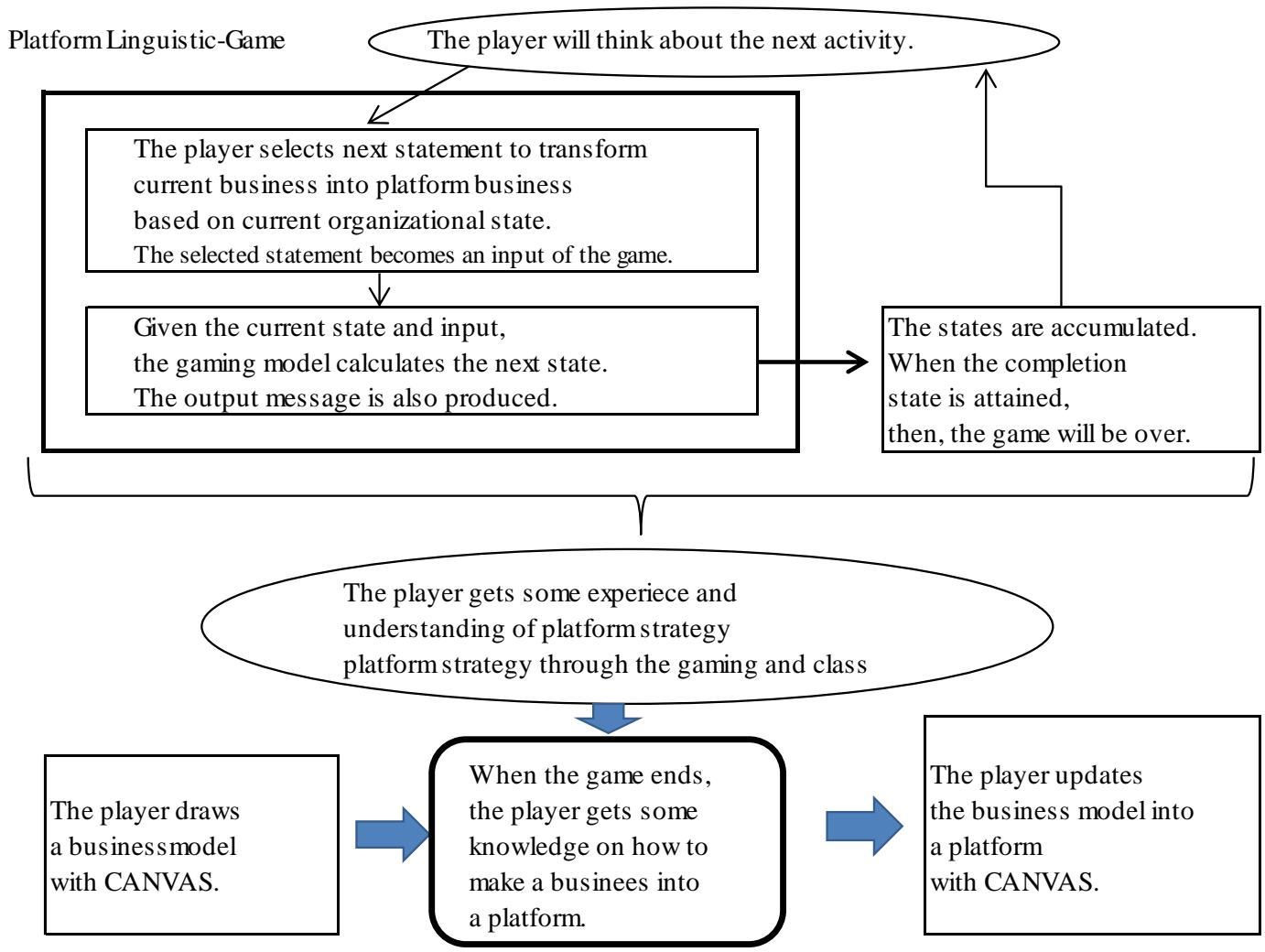

Figure 7. Use of a linguistic and qualitative game for business model development

A decision table represents a set of if-then rules. PfS has 14 rules. For instance, a rule (rule $\# 10)$ is stated as follows:
if the organizational state is in "Phase_1 in Searching Partners", and if the input is
"We will define the partnership to make competitive advantage" then the next state
is "We have decided partner(s)," and the output message is "We are trying to define
the whole business process that brings win-win partnership."

According to Teece [8], the dynamic capability of a company consists of sensing, capturing, and orchestration. The goal of using PfS game is to help people sense new partner user groups, business partners, and platform-business opportunities in general situation. In playing PfS game, players are strongly recommended to talk each other, ask each other, and answer each other. It would force them to be able to recognize personal bias, and possible new issue. Hopefully, it expands players' view on strategic dynamism, especially, in platform business. Figure 7 shows the situation. The players are requested to transform the business model into platform business. After that, they make paper how they changed the business.

Synthetic judgement drawn from the players of a linguistic and qualitative game is not always a silver bullet, so we have some room to extend it further. It is part of reason why we developed a gaming model by combination of qualitative and quantitative models. 


\section{Qualitative-control-of-quantitative-process (QCQP) model}

\subsection{QCQP MODEL}

In this paper, a gaming result is a case so that we can discuss and analyze how and what decisions make them realized.

A corporate strategy is sometimes expressed in natural language as discussed in Section 1. It is not a numerical plan. So, in order to include strategy into a game, the game should provide the input mechanism that allows players to input sentences expressed in natural language. Also, as usual real business, the strategy needs to be evaluated by financial or numerical performance measure.

Reference [12] focused on this loose-relation between qualitative decision and quantitative outcome of business organization. From an executive's point of view, Shimodaira and Terano called the situation "the CEO's dilemma," and had developed a qualitative-control-ofquantitative-process (QCQP) gaming model. Using that idea, [13] has further developed the same kind of model to be able to reproduce a Japanese beer company's success case. It makes players possible to learn how organizational capability for innovation will be cultivated by coordinating the top management's setting direction of business and gradual organizational development of operating capability that is guided and implemented by middle managers. Although their games aim to provide a gaming environment for people without knowledge of theory of management, the gaming models have elaborated combination of qualitative strategic input and quantitative operational calculation.

Reference [14] had developed an agent simulation gaming model to inspect propositions about Palm OS that are extracted from [15] and [16]. They defined four kinds of strategic factors of platform industry. The factors are called levers to manipulate a platform company as whole. With the gaming model, [14] showed that agent simulation method is also applicable for the model to find suitable (qualitative) combination of levels of those four factors in the successful history of Palm OS. But, since the number of possible combination of levels of four levers is quite huge, there might be more optimal and/or practical historical paths for the platform company to grow its business ecosystem. Such possibility should be explored by human players, if we can set appropriate gaming environment.

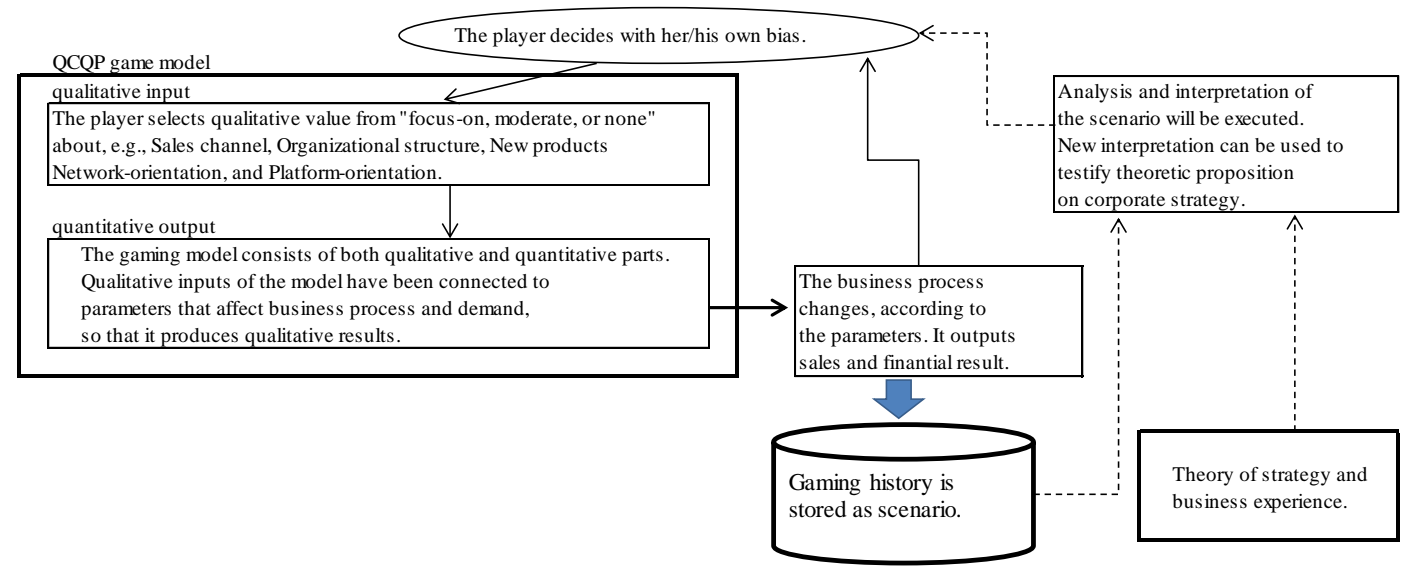

Figure 8. Qualitative-control-of-quantitative-process (QCQP) gaming model with strategy-theoretic proposition 
One of the points of this paper is to enhance possible interpretations for theories of strategy. QCQP gaming models seem to be useful for that purpose. When we try to make a QCQP model, we first need to focus on a proposition, or propositions, that seems for us to be important. The reason of that importance depends on the world view, and it is usually formulated or extracted from theories of strategy. For instance, Cusumano [16] provided six laws to win and stay in the top level in an industry. We can extract Cusumano's first law as "It is necessary for a manufacturer to be successful in transforming the business into platform, the company should grow not only its business but also the business ecosystem of the platform." This proposition requires explanation to be understood its meaning. So, we provide theory of platform business in the next subsection. When we focus on this proposition, we will make a QCQP model so that this proposition can hold true and might not stand true. By providing suitable qualitative input and usual quantitative business process, and by playing the model with experienced players, we will be able to find some strategic and /or operational insight in analyzing the resultant scenario of the game.

\subsection{Management Strategy of Platform Company}

\section{Basic structure of Palm platform}

We provide a simple explanation of platform business by referring Palm as an example [15]. Figure 9 shows the ecosystem and network effect of the Palm platform. When a user of a personal digital assistant (PDA) uses it, he or she works with both the PDA hardware and software on Palm OS. As the number of PDA users increases, opportunities to exchange data among users increase and it makes users beneficial. That is, the direct network effect works on the PDA device market, resulting in an improvement in the customer value of the PDA device. Likewise, the direct network effect also works on the software market: the value of software is increased by cooperation of software with various functions.

Another kind of network effect, called indirect network effect, is much important for platform to be attain successful growth on its business. It works as follows. If the number of PDA device users increases, business opportunities for software vendors of the PDA will increase. As the number of the software vendors which enter into the market increases, it can be expected that attractive applications software for PDA device users will increase. In other words, the indirect network effect will work between the PDA device market and the application software market.

The PDA and software that function on a platform, Palm OS, are called complements. The group of vendors of complement is a complementor. End users are important complementary group, though they do not produce any function on the platform. The system of platform and complementors is called the ecosystem of the platform. Figure 9 shows the ecosystem, except end-users. 


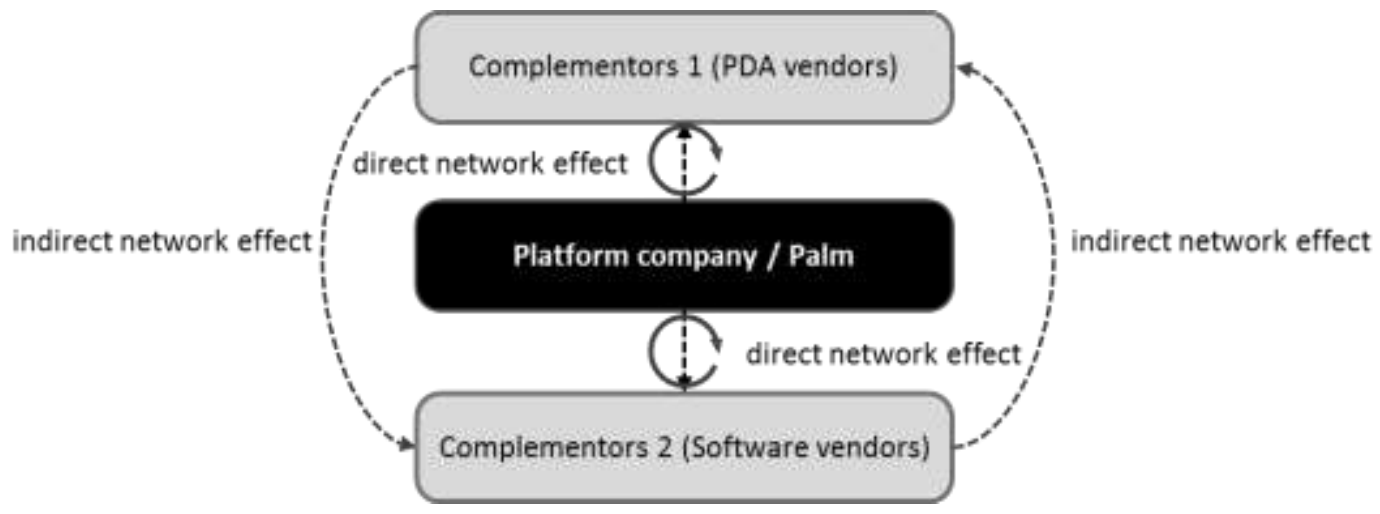

Figure 9. Ecosystem and network effect of Palm platform

\section{A brief history of Palm}

Before we proceed to the Palm platform game, we see a brief history of Palm, according to [17]. We simply focus on the growth of the Palm ecosystem. Fig.10 shows the development of Palm from the start until the thirteenth year.

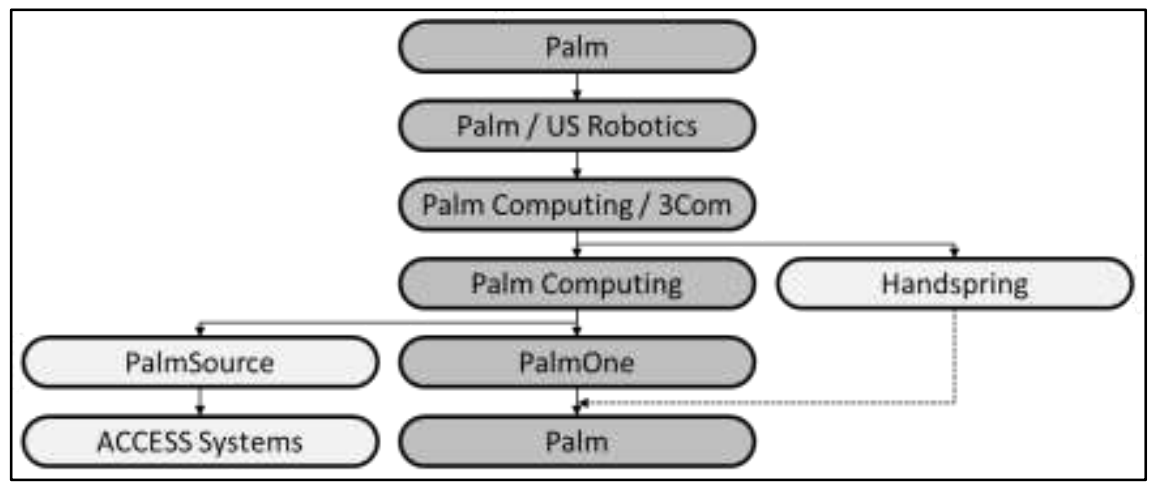

Figure 10. Growth of Palm

1992: Jeff Hawkins and established Palm Computing. Donna Dubinsky joined later.

1996: Palm sells 390,000 units of PalmPilot (PDA) by the end of 1996. Also, Palm provided its first development kit for software vendors.

1997: Palm sells over 1 million units. 3Com acquired US Robotics that acquired Palm Computing in 1995.

1998: Hawkins and Dubinsky left Palm Computing, and established Handspring.

1999: The first book for software development on Palm OS appears. (During 1999 to 2002, Palm OS's market share by PDA operating systems had been around $60 \%$. The Palm ecosystem had been most prosperous.)

2000: Palm goes public.

2003: Palm was divided into PalmSource for software (Palm OS), and PalmOne for hardware. (During 1996 to 2003, Palm OS's market share has been the top. The share dropped to $51 \%$ in 2003.)

2005: PalmSource is acquired by a Japanese software company. 


\section{Concept of platform strategy}

If a platform company intends to be profitable continuously, it is necessary to continually grow the platform. At least, it should not decline. Furthermore, a platform company needs to promote some innovation by complementors that increase the value of the platform as the whole ecosystem.

Since the ecosystem is a key for end-users to find their value in the platform, a strategy that seeks to maximize simply profit in a short run makes it difficult for the platform company to continue its growth. Platform company must properly control the allocation of the value created by the platform. Otherwise, innovation by complementors can not be expected or the platform can not grow. Based on [10], [16], and [18], the necessary condition (might not be sufficient, though) for the platform company to keep business continuity is stated as follows.

i) To grow the platform

ii) To keep complementors' profit

\subsection{Palm Gaming}

Theory of platform strategy and the Palm history explains strategy for a platform company and complementors. Those understanding is used to play the Palm game we developed, and the game result can be used to examine above two platform strategy statements, i) and ii) for growth. In order to play the game, we examine some issues on the business around the platform as follows.

\section{A. The Palm platform}

Palm is the platform company of Palm OS. A platform company manages the architecture of the platform, while complementors use the platform to develop hardware and/or software. Palm will decide the price of the information of the Palm OS architecture to sell the Palm PDA manufacturers and software vendors. The price could be zero.

\section{B. Licensing business of Palm OS}

Palm exclusively owns the right to license Palm OS. As the licensor, Palm can charges license fee to licensee. In hindsight, it was possible to open Palm OS as OSS (Open Source Software) from the beginning, and to get revenue from licensing business with devices and software running on Palm OS. In any case, Palm is responsible for continuously developing the Palm OS and providing an optimized OS for the evolution of CPUs and peripherals.

\section{Palm device manufacturer}

Palm PDA vendors are licensee. They can install Palm OS on their products and sell them to users. Since Palm OS needs a characteristic function such as handwriting input, it is inevitable for PDA and software vendors to contract with Palm. Then, they will be able to have a technical support and to make bundled software work correctly.

Hypothetically speaking, Palm could manufacture and sell PDA device and expand device market equipped with Palm OS. However, Palm is in an advantageous position as a Palm OS licensor, and Palm's entry into the PDA market may pose a threat to other PDA vendors, which may be a factor in hindering complementors' businesses.

\section{Application software vendors on Palm OS}

Software vendors cannot develop or sell software without a license agreement with Palm. It is also effective for software vendors to receive technical support such as SDK provided by Palm 
for developing high quality software.

Again, Palm could develop application software by themselves. By doing so, it is possible to improve the convenience of the PDA device and increase the product value. Palm, which can provide software integrated with Palm OS, might pose a threat to other software vendors. It may be a factor in hampering new entry.

\subsection{Procedure of gaming}

\section{A. Purpose of this gaming: Palm Game}

This gaming focuses on the first half of the Palm's business for about 13 years since Palm was founded in 1992. In other words, competition with external platforms such as mobile phones after 2005, which caused a definitive damage to the Palm platform, is not included.

Seven business people participated in the game as human players. Each player of this game develops a management strategy as Palm's business manager and competes to develop own company's business. In particular, it is required to consider the relationship with complementors.

As one round corresponds to about a year, each players executed with 10 rounds as one game. All games were executed independently, and each player's decision did not interfere with each other and each player got results individually.

\section{B. Decision variables}

Each player makes decisions regarding the following three items and inputs as shown in Figure 11 .

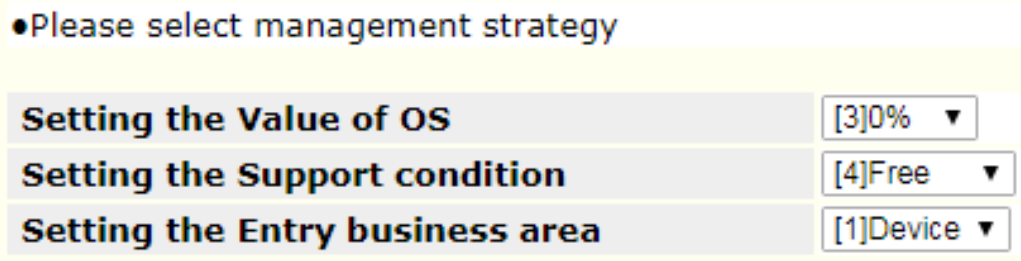

\section{$[3] 0 \%$ V \\ [4]Free $\quad \boldsymbol{V}$ \\ [1]Device $~$}

Figure 11. Player's Input window

The following is the list of possible input for respective input variables.

\section{Value of $O S$}

Determine the percentage of Palm OS occupied among total customer value created by PDA device. Three choices are provided:(1)10\%, (2) $5 \%$, (3) $0 \%$.

\section{Support condition}

Determine conditions for providing technical support to complementors. Four choices are provided. (1) All complementors must pay some price to Palm. (2) The PDA device vendors must pay to Palm, but the software vendors can freely have technical support. (3) The software vendors must pay to Palm, but the PDA vendors can freely have technical support. (4) Both vendors get free support. 


\section{Palm's Entry business area}

Determine to what extent Palm enters into the business area of complemetors' businesses. Four choices are provided. (1) Palm enters into both PDA and software. (2) Palm enters into PDA manufacturing. (3) Palm enters into the software development on Palm OS. (4) Palm does not enter any business but focuses on Palm OS.

The game proceeds round wise. That is, at a round every player should decides his/her input. Then our gaming environment, called Yokohama Business Gaming environment that is a cloud based server, calculates the model and shows the result like Figure 12 to players. Based on the result at the round, the players play at the next round. After running the game for some rounds, we get gaming result as like Figures 13 through 14. (Notice that respective team numbers are used for players.) Then, we can do interpretation and analysis.

\section{Input history and Performance}

\section{Term 03}

\begin{tabular}{|c|l|r|r|r|}
\hline Round: & $\mathbf{0 0}$ & $\mathbf{1 1}$ & $\mathbf{0 2}$ & \multicolumn{1}{c|}{$\mathbf{0 3}$} \\
\hline Value of OS & 0.0 & $0 \%$ & $0 \%$ & $0 \%$ \\
\hline Support condition & 0.0 & Free to all vendors & Free to all vendors & Free to all vendors \\
\hline Entry business area & 0.0 & Device and $\mathrm{App}$ & Device and App & Device and $\mathrm{App}$ \\
\hline
\end{tabular}

\begin{tabular}{|c|c|c|c|c|}
\hline Round: & 00 & 01 & 02 & 03 \\
\hline Market size actual & $1,000.0$ & $1,231.7$ & 772.1 & 507.7 \\
\hline Platform company profit & 0.0 & 91.7 & -3.0 & 1.8 \\
\hline Device vendors profit & 0.0 & -82.2 & -72.1 & -72.8 \\
\hline App vendors profit & 0.0 & -56.5 & -63.1 & -70.7 \\
\hline Round: & 00 & 01 & 02 & 03 \\
\hline Platform company cumulative profit & 0.0 & 91.7 & 88.7 & 90.5 \\
\hline Device vendors cumulative profit & 0.0 & -82.2 & -154.3 & -227.1 \\
\hline App vendors cumulative profit & 0.0 & -56.5 & -119.6 & -190.3 \\
\hline
\end{tabular}

Figure 12. Output example of round result (Term 3) 


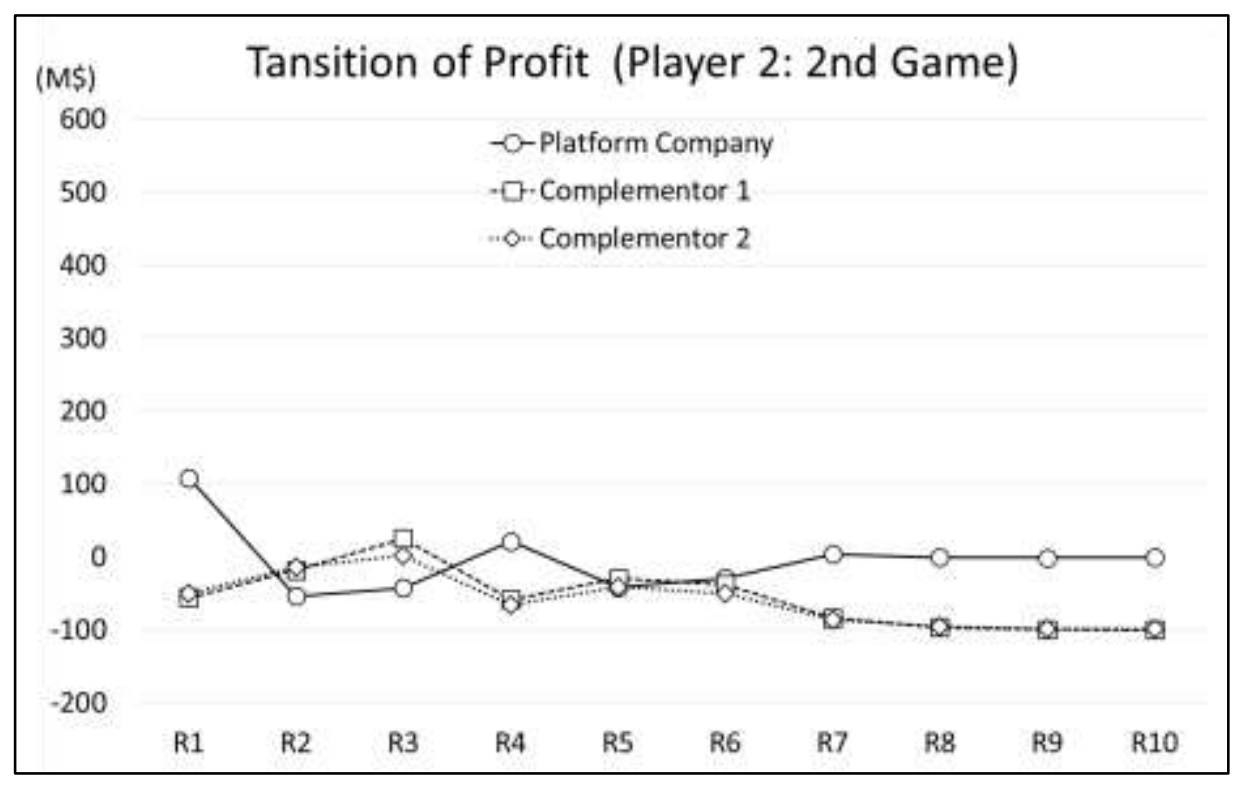

Figure 13(a). Game result of a player after 10 rounds at second play

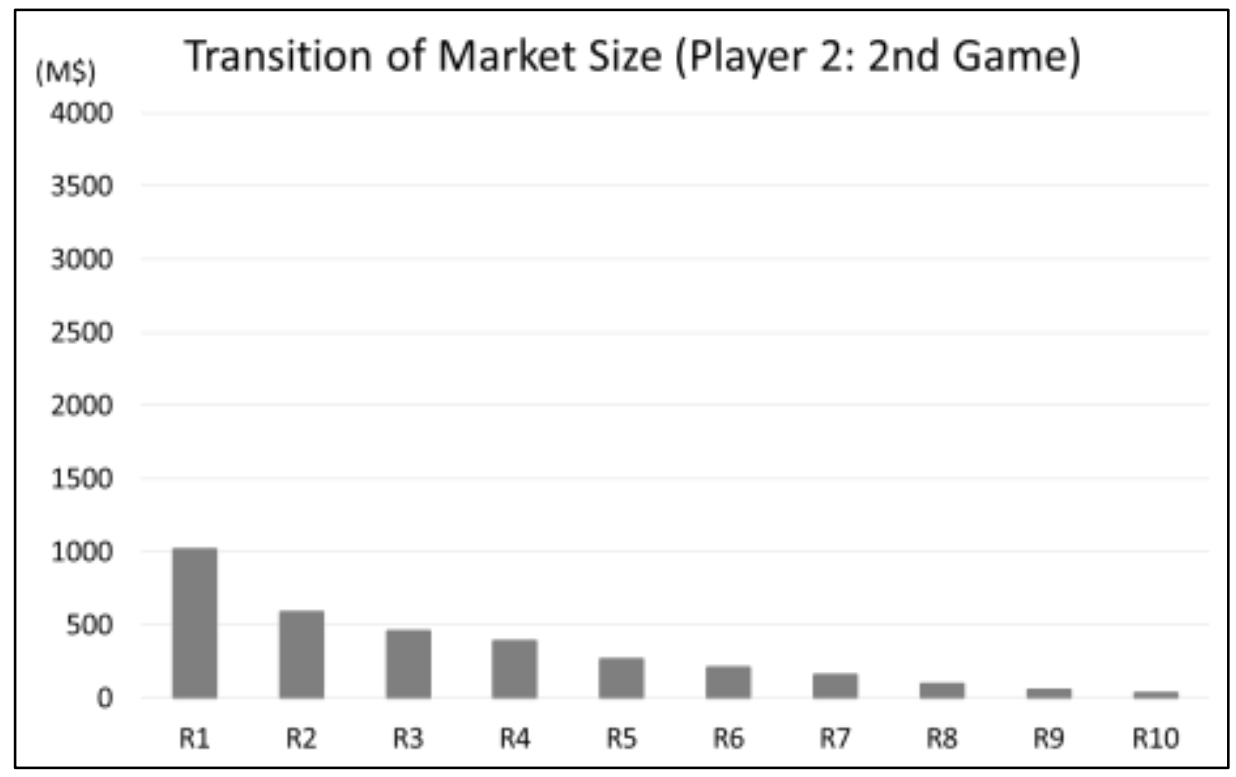

Figure 13(b). Market development at second play

We have played the game three times. Since the first play is to get familiar with this game, we analyze the second and third results. The players change their strategy somehow in respective plays. Figures 13 (a) and (b) show the player 2's result. Figure 13(a) shows the profits of the platform company, of PDA complementors, and of software complementors, respectively. Figure 13(b) shows the sum of those three types companies' sales.

In Figure 13(a) and (b) at the second play of the player 2, complementors seem to lost the 
incentive to participate in the platform at the beginning of the game, and then, the market shrunk and eventually entered into an unrecoverable reduced spiral.

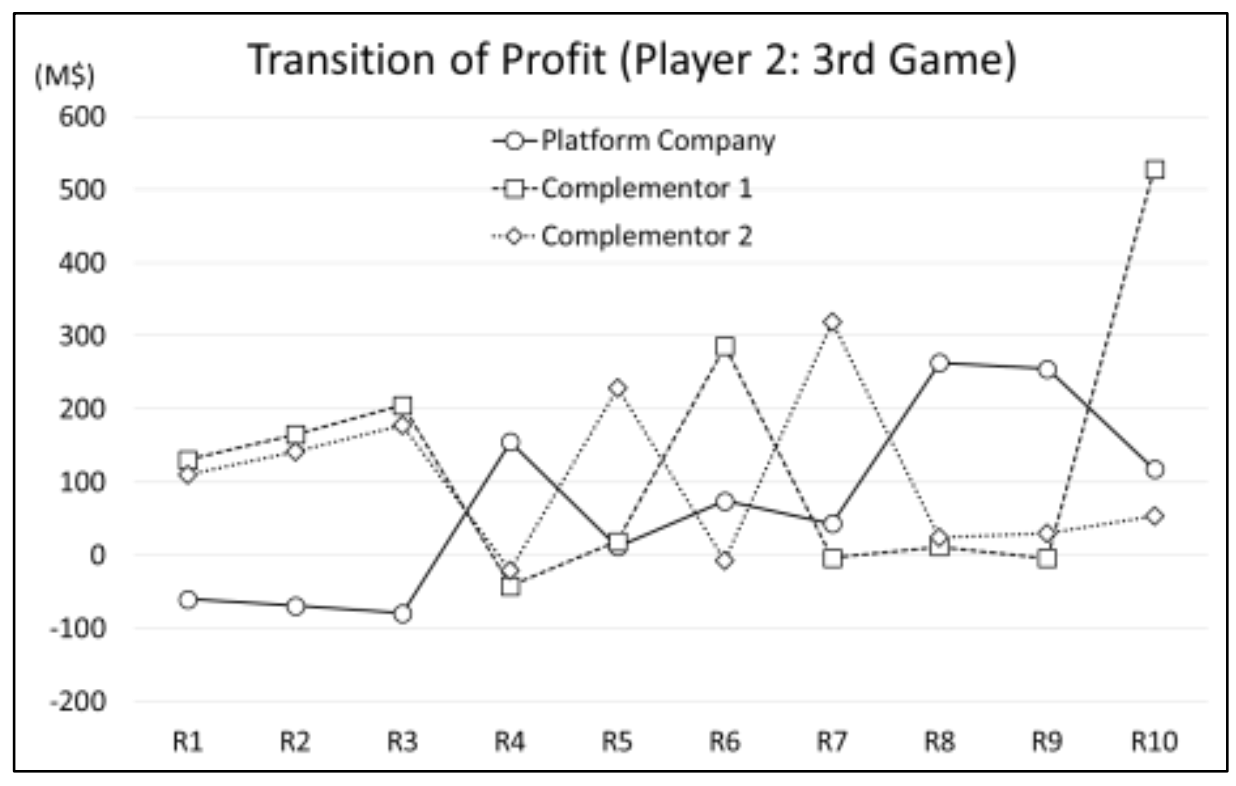

Figure 14(a). Game result of a player after 10 rounds at third play

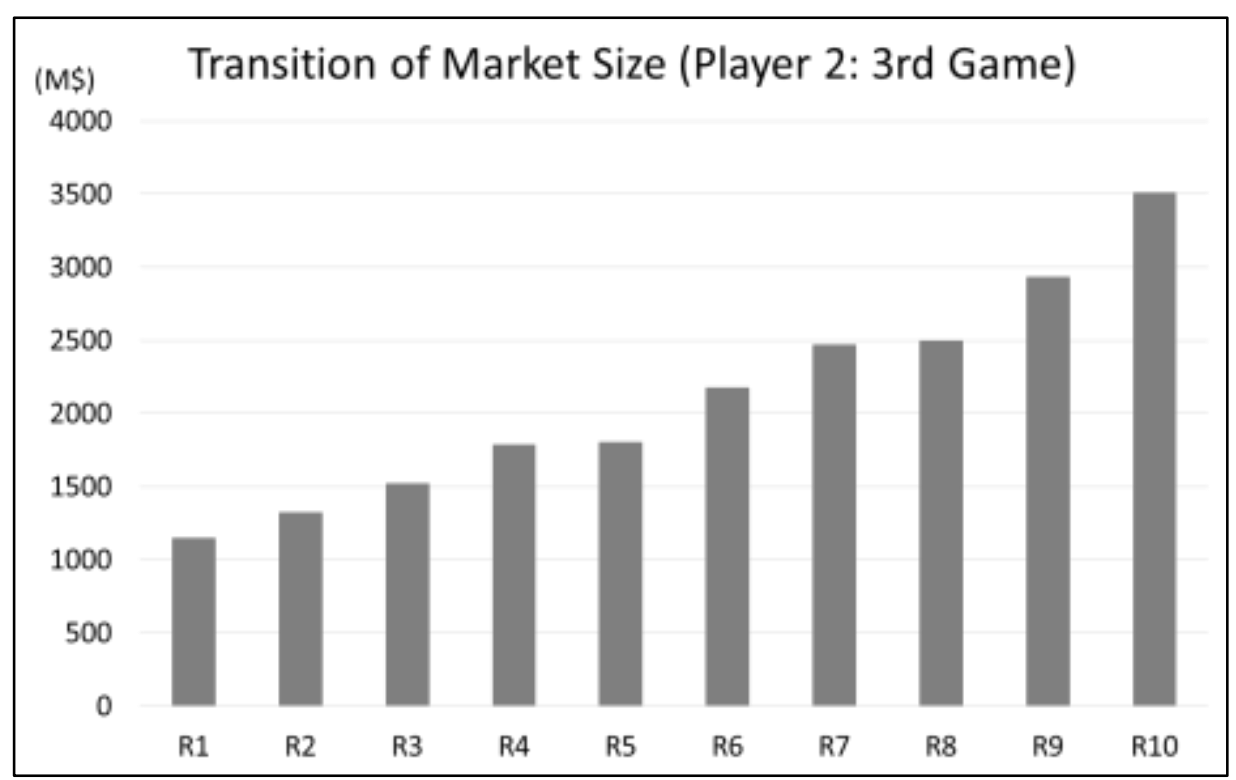

Figure 14(b). Market development at third play

In Figures 14(a) and (b), at the third play of the player 2, the platform gave complementors incentives to participate in the platform. By entering the enlarged spiral, the market was actively maintained and benefited the platform company and complementors. 
After discussing strategic issues about a platform and its ecosystem that includes complementors and end-users of the whole system, human players convinced the importance of the theoretical statement to grow the platform ecosystem by focusing on not only platform but complementors. We can say that QCQP gaming has provided miscellaneous issues to interpret such theoretical statements in real business situation.

\section{Concluding remark}

Theory of strategy has two kinds of difficulties with strategic propositions. We have surveyed three methods for applying gaming models to resolve the difficulties. Each method requires players' knowledge about a theory of strategy, and then the players play the game and check whether important propositions of the theory are true or false by examining gamed results as cases.

The three methods can resolve some aspects of the problematic situation of the research of strategy. We can characterize the methods as follows.

(1) A gaming transforms round-wise sequence of inputs to sequence of outputs, which is a gaming result. In the case of strategy games explained in this paper, such sequences of both inputs and outputs should be designed to correspond to certain proposition(s) of a theory of strategy. If a gaming result does not correspond to any strategic issue, then it is usually hard to find strategic implication of the gaming result, or it is not plausible that the result incurs human communication on strategic meaning.

The design needs to intend to refute proposition. As is stated in [19], an attitude to add only a positive case that supports a proposition does not provides us useful information or does not contribute to the scientific development of theory of strategy. When we try to refute a proposition, we refine the conditions of the proposition so that we can apply to specific situation. If the proposition stayed true even in such a new specific situation, then we can say that the proposition is also applicable to the new situation. The tested new condition could enhance meaningful business implications.

(2) A proposition on strategy has the form of general sentence. That is, a general proposition insists that for any organization, if a condition $\mathrm{P}$ holds true for an organization, then $\mathrm{Q}$ holds true for the organization. Since our business situation, that includes social, technological, and natural environment, has been always changing, the scope (the set) of organizations for which a proposition holds true is limited. Under this condition of theory of strategy and its propositions, three methods of gaming for strategy can offer a way to provide alternative cases that could be realized but not happened situations. Furthermore, as Greenwald and Kahn suggested, we showed a way how we can extract experiential knowledge explicitly in the gaming.

Since the three methods rely on subjective judgment in designing gaming with gaming models, the result does not seem to be dependent on the game setting. It is quite dependent on researchers. We need much consideration about that issue. Right now, QCQP models for theory of corporate strategy seem to be promising for theory of strategy.

\section{Acknowledgement}

This research has been partly supported by KAKENHI 26285083 and YNU Research Initiative and Promotion Organization for business simulation. 


\section{References}

[1] B.C. Greenwald, J. Kahn, Competition Demystified: A Radically Simplified Approach to Business Strategy, Portfolio, 2007.

[2] H. Mintzberg, "The fall and rise of strategic planning," Harvard Business Review, JanuaryFebruary, 1994.

[3] M. Tanabu and R. Sato "A Methodology for Business Analysis: Human-based Simulation of Corporate Strategy,” J. of ISCIE, 58 - 7, pp.288-294, 2014 (in Japanese)

[4] K. Eisenhardt, "Building Theories from Case Study Research," The Academy of Management Review, 14(4), 1989, pp.532-550.

[5] K. Eisenhardt and M. Graebner, "Theory Building From Cases: Opportunities And Challenges," Academy of Management Journal, Vol. 50, No. 1, 2007, pp.25-32.

[6] R. Sato, "How do you evaluate corporate strategy through gamification?" Poster Presentation in ISAGA, 2014, Dornbirn, Austria.

[7] J.B. Barney, Gaining and Sustaining Competitive Advantage, 2nd ed. Pearson Education, Inc, 2002.

[8] D. Teece, Dynamic Capabilities and Strategic Management, Oxford Univ Press, 2009.

[9] A. Osterwalder and Y. Pigneur, Business Model Generation: A Handbook for Visionaries, Game Changers, and Challengers, Wiley, 2010.

[10] H. Chesbrough, Open Services Innovation: Rethinking Your Business to Grow and Compete in a New Era, Jossey-Bass, 2011.

[11] M.Tanabu, R.Sato, H.Shirai, "Linguistic and qualitative games and its implication to dynamic capability," J. Yokohama Business Administration Society, Vol.35, No.2, 25-44, 2014. (in Japanese)

[12] T.Shimodaira and T.Terano "Bridging Business Modeling and Case Metod - How to Solve Presidents' Dilemma," Studies in Simulation and Gaming, 14(2), 144-156, (2004) (in Japanese)

[13] K. Nakano and T.Terano "Integrating a Learning System with Case Method and Business Gaming," Studies in Simulation and Gaming, 16(1), 13-27, (2006) (in Japanese)

[14] H. Sunaguchi, R. Sato, H. Shirai, "Design method for the platform strategy using agent simulation,” Proceedings for JASAG conference, 2016. (in Japanese)

[15] A. Gawar and M. Cusumano, Platform Leadership: How Intel, Microsoft, and Cisco Drive Industry Innovation, Harvard Business School Press, 2002. 
[16] M.A. Cusumano, Staying Power, Oxford University Press, 2010.

[17] D.S. Evans, A. Hagiu, R. Schmalensee, Invisible Engines: How Software Platforms Drive Innovation and Transform Industries, MIT Press, 2008.

[18] T.R. Eisenmann, G.G. Parker, M.V. Van Alstyne, "Strategies for Two-Sided Markets", Harvard Business Review, 2006, pp84-10.

[19] K. Popper, The Poverty of Historicism, Routledge and Kegan Paul, 1957. (Japanese translation by Iwasaki, A, NikkeiBP, 2013.) 